\title{
PEA, DSP E INTENCIONALIDADE PEDAGÓGICA: PERCEPÇÃO INGÊNUA OU DESVELAMENTO DA REALIDADE?
}

José Silva Quintas ${ }^{1}$

\begin{abstract}
Resumo
O artigo apresenta uma reflexão sobre o papel estruturante do Diagnóstico Socioambiental Participativo (DSP) para elaboração dos Programas de Educação Ambiental (PEA), exigidos como um dos Condicionantes de Licença pelo Instituto Brasileiro do Meio Ambiente e dos Recursos Naturais Renováveis (IBAMA), no marco da Educação Ambiental Crítica. Alerta para o risco de na realização do Diagnóstico Socioambiental, com a perspectiva de torná-lo radicalmente participativo, se partir da crença de que o povo sabe tudo e cair na armadilha do espontaneísmo pedagógico. E, desse modo, reforçar a percepção ingênua da realidade, em lugar de promover o seu desvelamento, pelos participantes do processo educativo, como objetiva o DSP. E, ainda, como conseqüência, esvaziar o papel do educador como organizador e mediador qualificado do processo de ensino-aprendizagem, que constitui a realização do DSP, com os sujeitos da ação educativa, colocando em seu lugar o chamado facilitador.
\end{abstract}

Palavras-chaves: Diagnóstico Socioambiental Participativo. Programa de Educação Ambiental no Licenciamento. Licenciamento Ambiental Federal. Educação Ambiental Crítica.

\section{PEDAGOGICAL INTENTIONALITY IN THE PARTICIPATORY ENVIRONMENTAL DIAGNOSIS (PED): AVOIDING THE NAIVE PERCEPTION TO UNVEIL THE REALITY?}

\begin{abstract}
In light of the Critical Environmental Educational Theory, this article analyzes the purpose of Participatory Environmental Diagnosis (PED) as a preparatory stage of the Environmental Education Program (EEP), which is required to obtain the Environmental License, given by the brazilian government. Examining the PED, the text focuses on the risk of radicalism, based on a naive belief that the people know everything. The radicalism prevents the unveiling of reality and removes the educator's role as organizer and qualified mediator of the teachinglearning process.
\end{abstract}

Keywords: Participatory Environmental Diagnosis (PED). Environmental Education Program (EEP). Environmental License. Critical Environmental Educational Theory.

\section{PEA, DSP Y INTENCIONALIDAD PEDAGÓGICA: ¿PERCEPCIÓN INGENUA O REVELACIÓN DE LA REALIDAD?}

\section{Resumen}

A la luz de la Teoría de la Educación Ambiental Crítica, este artículo analiza el propósito del Diagnóstico Socioambiental Participativo (DSP) como fase preparatoria del Programa de

\footnotetext{
${ }^{1}$ Educador e Analista Ambiental aposentado do IBAMA.
} 
Educación Ambiental (PEA), que se requiere para obtener la Licencia Ambiental, propuesta por el gobierno brasileño. Examinándose el DSP, el texto se centra en el riesgo de radicalismo, basado en la creencia ingenua de que las personas saben todo. El radicalismo impide la presentación de la realidad y elimina el papel del educador como organizador y mediador calificado del proceso de enseñanza-aprendizaje.

Palabras-clave: Diagnóstico Socioambiental Participativo. Programa de Educación Ambiental del Licenciamiento. Licenciamiento Ambiental Federal. Educación ambiental Crítica.

\section{Introdução}

A Educação Ambiental na Gestão Ambiental Pública ou Educação no Processo de Gestão Ambiental, como denominada inicialmente, pelos educadores do Instituto Brasileiro do Meio Ambiente e dos Recursos Naturais Renováveis (IBAMA), durante o processo de sua construção coletiva, é uma proposta pertencente ao campo da Educação Ambiental Crítica que toma o espaço da Gestão Ambiental Pública (GAP) como espaço de formulação e execução processual do ato pedagógico. Não se trata de uma nova Educação Ambiental, mas uma proposta cuja identidade político-ideológica se constitui com base na Educação Crítica e $a$ identidade operacional-temática na Gestão Ambiental Pública.

Compreende a Gestão Ambiental Pública (GAP) como processo de mediação de interesses e conflitos, entre atores sociais, pelo controle da destinação dos Recursos Ambientais na sociedade, realizada pelo Estado. E assume que o modo como o Estado pratica essa mediação define e redefine a distribuição de custos e benefícios na sociedade, em termos socioculturais, econômicos, temporais e espaciais. Assim, a Gestão Ambiental Pública, que, por princípio, deve ser praticada em nome do bem comum e do interesse público não é neutra (QUINTAS, 2009).

Em outras palavras

[...] qualquer ato que ordene o acesso e o uso de recursos ambientais, por mais justificável que seja, em princípio, também, contraria interesses legítimos e ilegítimos e, em muitos casos, põe em risco as condições materiais e simbólicas que devem garantir a satisfação das necessidades básicas, de grupos sociais já em condição de vulnerabilidade socioambiental. Ao pensar a Gestão Ambiental Pública, no Brasil, deve-se tomar como premissa estruturante que sua realização acontece em territórios, portanto em ambientes culturalmente diversos, que também, são portadores de diversidade biológica [...] (QUINTAS, 2009, p.53, grifos texto original)

Há grupos sociais que têm ou poderão ter seus modos e meios de vida radicalmente transformados por atos de gestão ambiental praticados pelo Poder Público. Não é incomum encontrar, em capitais nordestinas, meninas de 12 ou 13 anos sendo prostituídas e meninos nessa faixa de idade já envolvidos com o tráfego de drogas ilícitas e outras atividades de natureza equivalente. Em muitos casos, em virtude da expulsão de famílias de pescadores da área costeira, pela especulação imobiliária e por empreendimentos hoteleiros e imobiliários, muitos deles, inclusive, licenciados por órgãos ambientais.

Por ato de gestão ambiental entenda-se decisões do Estado, tais como de licenciar ou não um empreendimento ou atividade potencialmente poluidora, criar uma Unidade de Conservação de proteção integral, desafetar ou ampliar sua área, estabelecer o período de defeso de recursos pesqueiros, fazer enquadramento e/ou outorga de determinado corpo d'água, autorizar a extração manejada de recursos florestais, a supressão de vegetação etc. 
Distinta da GAP, a Gestão Ambiental Empresarial é praticada por iniciativa e decisão do empreendedor, de acordo a racionalidade empresarial (basicamente, diminuição de custos por eco-eficiência e marketing) ou por obrigação, em cumprimento de exigências legais. Já a GAP é sempre realizada pelo Estado, para regular a apropriação social dos recursos ambientais, na forma da Lei. Além do mais, a GAP é dever do Poder Público, existe para garantir Direitos Constitucionais ${ }^{2}$ e tem caráter mandatório.

Quando o Poder Público, ao praticar a GAP, somente leva em conta os interesses de determinados segmentos da sociedade, via de regra aqueles com maior poder de influência (econômico e político, principalmente) em suas decisões, em detrimento de outros grupos, beneficia uns poucos e transfere aos demais, com variada intensidade, os custos decorrentes do ato de gestão. Sendo que as populações em situação de vulnerabilidade socioambiental tendem a arcar com os maiores custos socioambientais, em geral por possuírem pouca ou nenhuma condição material, organizacional ou cognitivo-informacional para se articularem e defenderem seus modos e meios de vida. Nesse caso, a GAP se torna um instrumento produtor de injustiça social e ambiental, tirando muito de quem já tem pouco ou quase nada.

No Licenciamento Ambiental, como potencial instrumento de mitigação da injustiça social e ambiental, a Política Nacional de Meio Ambiente (PNMA), em um dos seus objetivos, estabelecido no inc. VII, art. $4^{\circ}$ obriga o "[...] poluidor e o predador [...] da qualidade ambiental a [...] recuperar elou indenizar os danos causados [...]" (BRASIL, 1981, s/p, grifos meus) instituindo o chamado princípio poluidor-pagador. Na prática, fundamentados nesse princípio os órgãos ambientais definem os Condicionantes de Licença, na forma de "medidas necessárias à mitigação de impactos ambientais negativos, do empreendimento ou atividade, nos meios físico, biológico e socioeconômico", conforme a Resolução Conama 001, em seu inc. III, artigo $6^{\circ}$ (BRASIL, 1986, s/p).

A identificação dos impactos negativos advém da análise dos impactos do empreendimento realizada no Estudo de Impacto Ambiental (EIA). Essa análise deve apresentar o prognóstico de magnitude. Relevância e distinguir: "[...] os impactos positivos e negativos (benéficos e adversos), diretos e indiretos, imediatos e a médio e longo prazos, temporários e permanentes; seu grau de reversibilidade; suas propriedades cumulativas e sinérgicas; [e] a distribuição dos ônus e benefícios sociais [...]"'(BRASIL, 1986,op.cit. s/p, grifos meus), de modo a fornecer os elementos necessários para definição,pelo órgão ambiental, sobre quais e quantos Condicionantes da Licença serão exigidos.

Como em outras atividades da GAP, os Programas de Educação Ambiental exigidos pelo IBAMA como Condicionantes de Licença (BRASIL, 2012,) no Licenciamento Federal são os instrumentos criados para dar consequência prática às determinações da Constituição Federal, da PNMA e da Política Nacional de Educação Ambiental (PNEA). Dentre os meios para garantir o direito ao meio ambiente ecologicamente equilibrado, a Constituição estabelece, no inciso VI, $\S 1^{\circ}$, como umas das obrigações do Estado brasileiro a "[...] promoção da Educação Ambiental em todos os níveis de ensino e a conscientização pública para preservação do meio ambiente [...]" (BRASIL, 1988, s/p).

Na PNMA a Educação Ambiental é assumida como um dos dez princípios, a ser aplicado na sua execução para que atinja seus objetivos. Prevê a Educação Ambiental no ensino formal e "[...]inclusive a educação da comunidade, objetivando capacitá-la para participação ativa na defesa do meio ambiente [...]" (BRASIL,1981, s/p).

\footnotetext{
2 Além do direito ao meio ambiente ecologicamente equilibrado, há outros direitos individuais e coletivos previstos na Constituição, que podem ser ameaçados caso haja ação danosa ou omissão do Estado na defesa e proteção ambiental.
} 
Do mesmo modo, os Programas de EA no Licenciamento devem obedecer aos Princípios, Objetivos e demais determinações da Política Nacional de Educação Ambiental (PNEA), que são os pressupostos pedagógicos e legais das práticas educativas, tanto na esfera da Educação Formal quanto da Não Formal. Reafirmam o compromisso da Educação Ambiental com valores e práticas essenciais ao processo de construção de uma sociedade mais democrática, solidária, social e ambientalmente justa e pacífica, na perspectiva da sua sustentabilidade (BRASIL, 1999).

Compromissos retomados pelo Conama na Resolução 422 (BRASIL, 2010, s/p) que define as Diretrizes "para conteúdos e procedimentos em campanhas, ações e projetos e programas" de EA e também, pelo Conselho Nacional de Educação, na Resolução 02 (BRASIL, 2012a, s/p), quando fixa as "Diretrizes Curriculares Nacionais para Educação Ambiental a serem observadas" na Educação Básica e Superior.

Quem acompanha os debates internacionais e locais sobre os chamados Problemas Ambientais Globais, observa que sustentabilidade e sustentável, quando referidos em documentos oficiais brasileiros e internacionais, corporativos, empresariais, de movimentos sociais populares e nos meios de comunicação, nem sempre têm o mesmo sentido nos diferentes discursos proferidos. Razão pela qual são tidos como termos polissêmicos, tais quais os termos meio ambiente, participação, emancipação, autonomia, Educação, Educação Ambiental entre os muitos que são reiterados no campo ambiental.

Assim, sustentabilidade pode ser tudo ou não ser nada. Para Henri Acselrad (1986, apud MARRUL, 2003, p.86), refere-se a "uma noção a que se pode recorrer para tornar objetivas diferentes representações e ideias [...] distintas e valores [que] vêm sendo [a ela] associadas [...] discursos em disputa pela expressão que pretende mais legítima”. Portanto, sustentabilidade pode ser usada para servir a todos os gostos e propósitos.Evidenciar e problematizar em seus processos educativos as diferentes apropriações da noção de sustentabilidade, suas implicações no cotidiano, para quê e a quem servem na sociedade, é um dos desafios para a Educação Ambiental.

Ignacy Sachs (2002), alertando que o termo sustentabilidade é comumente utilizado para se referir à sustentabilidade ambiental, enumera oito dimensões e respectivos critérios que confeririam esse atributo a uma sociedade. São critérios nas dimensões: Social, Cultural, Ecológica, Ambiental, Territorial, Econômica e Política (nacional) e Política (internacional), necessariamente, inter-relacionadas e interdependentes, que devem ser obedecidos para construção de uma sociedade sustentável. Sem dúvida, uma questão a ser problematizada na prática da EA com viés transformador.

O Brasil, apesar da fartura de recursos naturais, apresenta-se social e ambientalmente injusto com a maioria dos seus cidadãos. A maioria não usufrui plenamente dos direitos básicos da cidadania, influi pouco nas políticas públicas, é sub-representada nas instâncias legislativas, convive com riscos ambientais e tecnológicos, são trabalhadores sub-remunerados e muitos subempregados. Tal sociedade, nem de longe pode ser considerada perto da sustentabilidade.

A construção de um Brasil sustentável e democrático, sobretudo, por necessitar superar a injustiça social e ambiental e os privilégios de classe, mesmo precisando das Ciências e da Tecnologia é uma tarefa antes de tudo política, que depende da participação coletiva, organizada e qualificada dos seus cidadãos. Processo que deve contar com a imprescindível contribuição da Educação praticada com visão crítica, participativa, transformadora e emancipatória.

No plano da execução, a PNEA incumbe aos órgãos do Sisnama de "promover ações de educação ambiental integradas aos programas de conservação, recuperação e melhoria do meio ambiente" (BRASIL, 2002, s/p.) e, conforme seu Decreto regulamentador: 
[...] deverão ser criados, mantidos e implementados, sem prejuízo de outras ações, programas de educação ambiental integrados: [...] às atividades de conservação da biodiversidade, de zoneamento ambiental, de licenciamento e revisão de atividades efetivas ou potencialmente poluidoras, de gerenciamento de resíduos, de gerenciamento costeiro, de gestão de recursos hídricos, de ordenamento de recursos pesqueiros, de manejo sustentável de recursos ambientais, de ecoturismo e melhoria de qualidade ambiental [...]" (BRASIL, 2002, s/p).

Embora tratando do mesmo objeto, o meio ambiente, as duas políticas apresentam conceituações distintas a seu respeito. Em outras palavras, apesar de se referirem a um mesmo termo não falam da mesma coisa. De acordo com suas finalidades, a PNMA entende que meio ambiente compreenda "o conjunto de condições, leis, influências e interações de ordem física, química e biológica, que permite, abriga e rege a vida em todas as suas formas" (BRASIL, 1981, s/p); já o Conama, na Resolução 001(BRASIL, 1986), utiliza para formular o conceito de Impacto Ambiental, desdobramento do conceito de Poluição, estruturante na prática do Licenciamento. É por meio desse conceito que a PNMA dialoga com a noção de meio ambiente, um dos princípios da PNEA produzindo uma convergência no plano operacional, configurada na concepção do PEA e do PEAT (Programa de Educação Ambiental dos Trabalhadores), instituídos pela instrução normativa - IN 02 (BRASIL, 2012).

Por outro lado, o PEA e PEAT são singulares em relação aos demais Condicionantes. Nos outros, as ações mitigatórias ${ }^{3}$ são intervenções técnicas e ou econômicos sobre os meios físiconatural e social, objetivando a prevenção tanto de riscos quanto a reversão de danos, em um deles ou em ambos, decorrentes dos impactos ambientais negativos do empreendimento ou atividade sob licenciamento.Podem ter caráter informativo ( comunicação social),restaurador( de área degradada, ecossistema,estoque pesqueiro etc.), controlador ( rastreabilidade de resíduos,tratamento de efluentes, monitoramento de reservatórios hídricos etc.), compensatórias(reassentamento de populações, ampliação de infraestrutura urbana e de serviços públicos,indenizações etc.), entre outros.

\section{O Diagnóstico Socioambiental Participativo e a Intencionalidade Pedagógica}

No PEA a prática é educativa, portanto, com o objetivo de desenvolver capacidades com pessoas, para que em ação coletiva, organizada e qualificada:

a) decodifiquem as múltiplas dimensões da realidade socioambiental da área de influência direta e indireta do empreendimento;

b) ao mesmo tempo, atuem nela objetivando a mitigação e ou compensação dos impactos ambientais negativos e;

c) também, contribuam para construção de uma sociedade justa democrática e sustentável em suas múltiplas dimensões.

O PEA se corporifica a partir de processos de ensino-aprendizagem, organizados para construção de projetos específicos de EA, inicialmente, com os sujeitos da ação educativa dos grupos sociais prioritários. Aqueles afetados por impactos ambientais negativos da área de influência do empreendimento. Projetos em conformidade com as agendas de prioridades desses grupos. No ponto de partida o projeto do projeto, assim, pode ser constituído por um

\footnotetext{
${ }^{3}$ Considero que a mitigação tomada em sentido amplo,contém a noção de compensação.
} 
ou mais projetos de EA, cuja elaboração deve ser compatível, conforme as Bases Técnicas, anexas à IN 02/2012:

[...] com a tipologia do empreendimento/atividade licenciado sua área de influência relativa ao meio socioeconômico e as especificidades dos grupos sociais afetados [...] pelos impactos ambientais negativos. [E tem] [...] como finalidade, a qualificação e organização destes atores sociais para a proposição e/ou formulação e implementação dos projetos socioambientais de mitigação e/ou compensação, bem como o monitoramento e avaliação da sua efetividade [...] (BRASIL, 2012, s/p).

Ainda, de acordo com asa Bases Técnicas, a elaboração de cada projeto que comporá o PEA dependerá da identificação de problemas, conflitos e potencialidades socioambientais (CARVALHO; SCOTTO, 1995, apud QUINTAS, 2009, p.72) e respectivos grupos sociais afetados - potenciais sujeitos da ação educativa - e, dentre eles os prioritários, bem como das ações prioritárias definidas com esses grupos durante a realização do Diagnóstico Socioambiental Participativo (DSP).

O elemento participativo, que qualifica o DSP e os produtos dele esperados, implica em concebê-lo como um processo educativo fundamentado em metodologias participativas,

[...] entendidas como recursos técnico-pedagógicos que objetivam a promoção do protagonismo dos diferentes grupos sociais [...] na construção e implementação do PEA. [...] em articulação com Políticas Públicas dos três níveis de governo, com projeção [...] na área de influência do empreendimento [...]"(BRASIL, 2012, s/p, grifos meus).

Esses recursos técnico-pedagógicos ou procedimentos metodológicos não devem ser confundidos com a concepção metodológica ou metodologia que deve mediar a realização do Diagnóstico, a construção do PEA e dos atos pedagógicos necessários (QUINTAS, 2009, op.cit.).

Portanto, o DSP articula uma prática científica com uma prática pedagógica objetivando desvelar determinada realidade socioambiental para transformá-la, por meio de um ou mais Projetos de EA, que integrarão o PEA. Pressupõe a participação coletiva de pessoas do lugar e fundamenta-se no diálogo de saberes, em princípio, provenientes de diferentes visões de mundo. Considera, ainda, como inseparáveis os atos de conhecer, aprender e agir sobre a realidade. Realidade que, segundo Arruda (1986, apud Vasconcelos, 1989, p.100, grifo meu), deve ser entendida:

[...] como processo multidimensional, complexo que tem aspectos "transitórios" e aspectos "permanentes", aspectos visíveis e aspectos invisíveis, aspectos materiais e aspectos não materiais, aspectos específicos e aspectos gerais, uns agindo sobre os outros em forma de contraposição, de conflito, de contradição.

Portanto, trata-se de "realidade como movimento histórico, e não como uma externalidade objetiva" (GANTOS, 2016, p.14), cujo desvelamento exige uma Educação com perspectiva crítica, portanto transformadora e emancipatória.

Nesse sentido, o DSP dialoga com as concepções de Pesquisa-Ação propostas por João Bosco Pinto (PINTO, 1986) e Michel Thiollent (THIOLLENT,1992). Para o primeiro, a PesquisaAção como prática científica "busca a produção coletiva de conhecimento para uso coletivo" (PINTO, 1986, p.34). Para o segundo, trata-se de

[...] um tipo de pesquisa social com base empírica que é concebida e realizada em estreita associação com uma ação ou com a resolução e um problema coletivo e no qual [grifo meu] os pesquisadores e os participantes representativos da situação investigada ou do problema estão envolvidos de modo cooperativo ou participativo [...] (THIOLLENT, 1992, p. 14). 
Como prática pedagógica tem com estruturante o processo dialógico entre portadores de saberes diferenciados (equipe externa e comunidade local), que confrontados frente ao concreto devem produzir um novo saber sobre a realidade investigada bem como as ações, capazes de viabilizarem as transformações necessárias. Se dialógico, desse processo devem emergir grupos sociais específicos, com autonomia para articularem estratégias de obtenção dos meios necessários para implementação das ações delineadas. Estratégias ou cursos de ação possíveis, que podem necessitar de capacidades nos campos político, organizacional e cognitivo-informacional, para que o grupo social faça escolhas com maiores chances de sucesso e consiga implementá-las. Inclusive, como buscar a articulação dos projetos que constituem o PEA, com Políticas Públicas correlatas e instrumentos de gestão, como prevê a Instrução Normativa (BRASIL, 2012).

No caso do DSP, o problema seria como realizar o processo dialógico, onde são confrontados saberes diferenciados entre sujeitos coletivos de mundos diversos - equipe externa ${ }^{4} \mathrm{e}$ comunidade local - para identificarem e analisarem causas, consequências, responsabilidades e modos de abordagem de possíveis problemas, conflitos e potencialidades socioambientais decorrentes de impactos ambientais produzidos, direta ou indiretamente, pelo empreendimento.

Nessa perspectiva, o diálogo somente se processará, como ensina Paulo Freire, se for superada a "contradição educador [equipe externa] - educando [grupos sociais], de tal maneira que se façam ambos, simultaneamente, educadores e educandos", rechaçando o que chama de "concepção bancária de educação". Para ele, "na concepção 'bancária' que estamos criticando, para a qual a educação é um ato de depositar, transferir, de transmitir valores e conhecimentos, não se verifica nem pode verificar-se esta superação" (FREIRE, 1974, p.67, grifo meu). Tudo isto objetivando a produção da autonomia por meio do protagonismo da comunidade e de grupos sociais específicos na construção de projetos de mitigação e ou compensação, por eles definidos como necessários para lidarem com as condições ambientais observadas no Diagnóstico.

Porém, sem cair na armadilha nem do extensionismo autoritário (FREIRE,1975), que postula que o povo, por não dominar a Ciência e a Técnica da modernidade, é incapaz de criar soluções adequadas às suas necessidades. Nessa concepção, o problema de aprendizagem se resolveria com procedimentos metodológicos capazes de facilitar a absorção do ensinado (conhecimentos e habilidades) para ser reproduzido pelo aprendiz. Na prática, consiste na prescrição de modos de conduta pessoal ou para enfrentamento de uma determinada situação, a priori assumida por quem prescreve como a melhor para outro, como se este não tivesse capacidade para fazer escolhas.

Tampouco, na armadilha do espontaneísmo pedagógico que acredita que o povo, por viver o dia a dia de determinada realidade, sabe tudo sobre ela e não precisa de outros conhecimentos, para construção de soluções para superar as condições objetivas que vivencia. Uma espécie de extensionismo com sinal trocado.

Portanto, a qualidade da relação pedagógica (se dialógica ou bancária/extensionista) a ser estabelecida dependerá de como é concebido o sujeito pedagógico na intencionalidade pedagógica que direcionará o planejamento da prática educativa. Sujeito pedagógico, que, segundo Adriana Puigrós deve ser "entendido como o vínculo entre educador, educando e a produção simbólica que surge de tal vínculo" (PUIGRÒS, 1994, p. 16, tradução livre).

\footnotetext{
${ }^{4}$ Considero educadores, técnicos, pesquisadores que implementam e ou assessoram a realização do DSP e os técnicos do órgão licenciador que fazem seu monitoramento,
} 
Tanto no extensionismo quanto no espontaneísmo pedagógico, o modo como foi concebido o sujeito pedagógico, qualificado como passivo em um dos pólos de cada relação, faz com que o diálogo educador-educando não aconteça, na medida em que, da interação não emerge produção simbólica (aprendizagem mútua), mas apenas transmissão unidirecional de saberes, no máximo com sua reprodução, como esperada, quando se adota concepção "bancária de Educação" (FREIRE, 1974, p.67). Em decorrência, não há constituição do sujeito pedagógico emancipado (no caso os (grupos sociais da comunidade), mas somente domesticado. Nessa hipótese, tem-se um DSP bancário que, certamente, não servirá aos interesses e necessidades dos grupos sociais impactados negativamente pelo empreendimento. Portanto, no processo educativo será a natureza do vínculo que se estabelece entre educador e educando (dialógico ou não), que determinará a emergência ou não do sujeito pedagógico emancipado. Se a relação entre educador e educando for do tipo emissor (educador) e receptor (comunidade) ou ao contrário, há transmissão de informações em lugar de produção simbólica, portanto, reprodução do informado. Em ambos os casos, a disjunção substitui o diálogo e o processo não permite que haja a constituição do sujeito pedagógico emancipado. No primeiro caso, o educador impõe sua visão de mundo, pensa que sabe o que é bom ou ruim para a comunidade, criando uma relação de dependência e subordinação.

No espontaneísmo pedagógico, o educador assume uma posição de neutralidade na relação, evitando interferir na autonomia, na percepção e na ação da comunidade sobre sua realidade. Assim, transmuta-se em facilitador, esvaziando o papel do educador como organizador e mediador qualificado do processo de ensino aprendizagem, como se acreditasse que a realidade é literal e, assim, despolitizando o ato educativo.

Como o ato educativo sempre pressupõe uma intencionalidade, o modo como se concebe o sujeito pedagógico é condição necessária para o seu planejamento e execução. Num processo educativo que objetive contribuir para transformar a realidade e emancipar pessoas e grupos sociais, portanto, dialógico por definição, não há espaço para o que Adriana Puigrós denomina "Mitificação da produção espontânea das massas e desqualificação do papel do educador e da cultura socialmente acumulada" (PUIGRÒS, 1994, p. 16, trad. livre, grifo meu).

Nessa perspectiva, o educador como um facilitador da aprendizagem dos conhecimentos populares abstém-se de propor a abordagem de outros saberes no processo educativo. Dessa forma, a comunidade deve ser blindada de influências exógenas e o educador, em sua neutralidade, poderá contribuir durante o ato pedagógico, apenas como mediador e sistematizador dos trabalhos sem interferir no seu conteúdo.

No DSP equivaleria assumir que a comunidade não necessite de conhecimentos e habilidades necessárias para participar da sua realização, ou que ela desempenhe somente o papel de informante. Noções básica sobre a questão ambiental, legislação ambiental, cidadania, GAP no Sisnama e no Singreh, procedimentos para licenciar, condicionantes, impactos ambientais, políticas públicas e outras, são essenciais para os grupos sociais participarem de modo qualificado na elaboração do Diagnóstico. Nesse sentido, são imprescindíveis para a identificação dos problemas, conflitos e potencialidades socioambientais, assim como para analisar, causas, consequências dos impactos ambientais negativos, produzidos direta ou indiretamente pelo empreendimento em sua área de influência E, também, para a participação dos grupos locais na proposição, implementação monitoramento e avaliação dos projetos e programas de mitigação e de compensação exigidos nos Condicionantes.

Para Puigròs (1994 ):

[...] o estabelecimento de um vínculo dialógico entre educador e educando é sempre produto de um triunfo de oprimidos, sintoma de uma dura luta, e supõe a criação de novas 
articulações entre os saberes populares tradicionais e os modernos, entre a linguagem de uns $e$ outros, entre as experiências, entre as histórias. Nas novas formas de relação têm que existir uma hegemonia dos interesses populares reais. Eles (como expressão concreta e histórica e não mítica), mais que qualquer paradigma doutrinário, são os que têm que impor uma ordem à nova cultura que o vínculo pedagógico dialógico contribui para produzir. (PUIGRÒS, 1994, p. 17, trad. livre, grifo meu).

Nesses termos não seria concebível um DSP unidimensional para ser realizado apenas com base nos conhecimentos próprios da comunidade em uma "realidade multidimensional e complexa" (ARRUDA 1986, apud VASCONCELOS, 1989, p.100), que precisa de permanente decifração para ser compreendida e transformada.

Vale lembrar que as questões afetas diretamente ao Licenciamento, na prática estão relacionadas com outras dimensões da realidade. Como se sabe, essas dimensões (política, econômica, sociocultural, legal ética etc.), necessariamente inter-relacionadas e interdependentes, podem aparecer durante a realização do Diagnóstico e surpreender os participantes. Operar nesse nível de complexidade exige uma interdisciplinaridade para além do território do saber oficial, que incorpore o saber da comunidade.

\section{Referências}

BRASIL. Lei 6.938, de 31 de agosto de 1981. Dispõe sobre a Política Nacional do Meio Ambiente, seus fins e mecanismos de formulação e aplicação, e dá outras providências. Brasília: Casa Civil, 1981. Disponível em: < http://www.planalto.gov.br/ccivil_03/leis/L6938.htm>. Acesso em: 1 set. 2016.

BRASIL. Ministério do Meio Ambiente. Conselho Nacional do Meio Ambiente. Resolução Conama $N^{o}$ 001, de 23 de janeiro de 1986. Brasília: MMA/CONAMA, 1986. Disponível em: < http://www.mma.gov.br/port/conama/res/res86/res0186.html>. Acesso em: 1 set. 2016.

BRASIL. Constituição Da República Federativa do Brasil de 1988. Brasília: Senado Federal, 1988. Disponível em: <http://www.planalto.gov.br/ccivil_03/Constituicao/Constituicao.htm>. Acesso em: 1 set. 2016.

BRASIL. Lei $n^{\circ}$ 9.795, de 27 de abril de 1999. Dispõe sobre a educação ambiental, institui a Política Nacional de Educação Ambiental e dá outras providências. Brasília: Casa Civil, 1999. Disponível em: <http://www.planalto.gov.br/ccivil_03/leis/L9795.htm>. Acesso em: 1 set. 2016.

BRASIL. Decreto 4281, de 25 de Junho de 2002. Regulamenta a Lei oㅜ 9.795, de 27 de abril de 1999, que institui a Política Nacional de Educação Ambiental, e dá outras providências. Brasília: Casa Civil, 2002. Disponível em: <http://www.planalto.gov.br/ccivil_03/decreto/2002/d4281.htm>. Acesso em: 1 set. 2016.

BRASIL. Ministério do Meio Ambiente. Conselho nacional do Meio Ambiente. Resolução Conama $N^{o} 422$, de 23 de março de 2010. Estabelece diretrizes para as campanhas, ações e projetos de Educação Ambiental, conforme Lei 9.795, de 27 de abril de 1999, e dá outras providências. Brasília: MMA/CONAMA, 2010.2 Disponível em: <http://www.mma.gov.br/port/conama/res/res10/res42210.pdf>. Acesso em: 1 set. 2016.

BRASIL. Instituto Brasileiro de Meio Ambiente e Recursos Renováveis - IBAMA. Instrução Normativa $N^{o}$ 2, de 27 de março de 2012. Brasília: MMA/IBAMA, 2012. Dispõe sobre licenciamento ambiental. 
<https://www.ibama.gov.br/licenciamento/modulos/arquivo.php?cod_arqweb=in_02_2012>. Acesso em: 1 set. 2016.

BRASIL. Ministério da Educação. Conselho Nacional de Educação. Resolução $C N E / C P N^{o} 2$, de 15 de junho de 2012. Estabelece as Diretrizes Curriculares Nacionais para a Educação Ambiental. Brasília: MEC/CNE/CP, 2012a. Disponível em: $<$ http://portal.mec.gov.br/index.php?option=com_docman\&view=download\&alias=10988-rcp002-12pdf\&category_slug=maio-2012-pdf\&Itemid=30192>. Acesso em: 1 set. 2016.

FREIRE, P. Pedagogia do oprimido. Rio de Janeiro: Paz e Terra, 1974.

FREIRE, P. Extensão ou comunicação? 2 ed. Rio de Janeiro: Paz e Terra, 1975.

GANTOS, M. (Org.) et al. A Caravana Territórios do Petróleo: ressignificando a educação ambiental na Bacia de Campos. Campos dos Goytacazes: Editora da Universidade Estadual do Norte Fluminense Darcy Ribeiro, 2016.

MARRUL FILHO, S. Crise e sustentabilidade no uso dos recursos pesqueiros. Brasília: Edições IBAMA, 2003.

PINTO, J. B. G. A Pesquisa-Ação como Prática Social. Rev. Contexto e Educação, Ijuí, Ano I, n. 2, p.27- 46, Ab./Jun. 1986.

PUIGRÒS, A. Historia y Prospectiva de la Educación Popular Latinoamericana. In: Gadotti, M.; Torres, C. A. (Orgs). Educação Popular Utopia Latino-Americana. São Paulo: Cortez:/Ed. USP, 1994, p.7-22

QUINTAS, J. S. Educação no Processo de Gestão Ambiental Pública: a construção do ato pedagógico. In LOUREIRO, C. F. B; LAYRARGUES, P. P.; CASTRO, R. S. (Orgs.). Repensar a Educação Ambiental: um olhar crítico. São Paulo Cortez, 2009. p.33-79..

SACHS, I. Caminhos para o desenvolvimento sustentável. Rio de Janeiro: Garamond, 2002.

THIOLlENT, M. Metodologia da Pesquisa-Ação. 5 ed. São Paulo: Cortez/Autores Associados, 1992.

VASCONCELOS, I. A metodologia enquanto ato político da prática educativa. In: CANDAU, V.M. (Org.) Rumo a uma nova didática. 2 ed. Petrópolis: Vozes, 1989. p. 97-104. 